\title{
Role of MicroRNA in Visceral Pain
}

\author{
Jian Zhang and Banani Banerjee* \\ Division of Gastroenterology and Hepatology, Department of Medicine, Medical College of Wisconsin Milwaukee, WI , USA
}

The long-lasting nociceptive transmission under various visceral pain conditions involves transcriptional and/or translational alteration in neurotransmitter and receptor expression as well as modification of neuronal function, morphology and synaptic connections. Although it is largely unknown how such changes in posttranscriptional expression induce visceral pain, recent evidence strongly suggests an important role for microRNAs (miRNAs, small non-coding RNAs) in the cellular plasticity underlying chronic visceral pain. MicroRNAs are small noncoding RNA endogenously produced in our body and act as a major regulator of gene expression by either through cleavage or translational repression of the target gene. This regulation is essential for the normal physiological function but when disturbed can result in pathological conditions. Usually one miRNA has multiple targets and target mRNAs are regulated in a combinatorial fashion by multiple miRNAs. In recent years, many studies have been performed to delineate the posttranscriptional regulatory role of miRNAs in different tissues under various nociceptive stimuli. In this review, we intend to discuss the recent development in miRNA research with special emphases on miRNAs and their targets responsible for long term sensitization in chronic pain conditions. In addition, we review miRNAs expression and function data for different animal pain models and also the recent progress in research on miRNA-based therapeutic targets for the treatment of chronic pain.

(J Neurogastroenterol Motil 2015;21:159-171)

\section{Key Words}

Chronic Pain; MicroRNAs; mRNA; Visceral Pain

\section{Introduction}

The etiology of chronic visceral pain is complex and the underlying mechanism is difficult to understand. Initially, the pain originates from the dysfunction and/or inflammation of organs including the urinary bladder (interstitial cystitis), hindgut (colitis and irritable bowel syndrome [IBS]), uterus (fibroids and endometriosis), ureter (ureteral calculosis) and prostate (prostatitis). ${ }^{1-3}$ In chronic stage, the pain is not restricted to one organ, but often overlaps to other visceral and somatic structures (somatic mechanical and thermal allodynia), ${ }^{4,5}$ In general, visceral hypersensitivity can occur due to ${ }^{2}$ sensitization of primary sensory afferents innervating the viscera, ${ }^{1}$ hyperexcitability of spinal ascending neurons (central sensitization) receiving synaptic input from the viscera, and/or ${ }^{3}$ dysregulation of descending pathways that modulate spinal nociceptive transmission. Studies in rodents have documented that pelvic organs including bladder, colon and reproductive organs share a common spinal pathway to transmit signals to supra-spinal sites by (1) peripheral axonal dichot-

Received: February 18, 2015 Revised: March 19, 2015 Accepted: March 27, 2015

(c) This is an Open Access article distributed under the terms of the Creative Commons Attribution Non-Commercial License (http://creativecommons. org/licenses/by-nc/3.0) which permits unrestricted non-commercial use, distribution, and reproduction in any medium, provided the original work is properly cited.

*Correspondence: Banani Banerjee, PhD

Division of Gastroenterology and Hepatology, Department of Medicine, Medical College of Wisconsin Milwaukee, 8701 Watertown Plank Road, Milwaukee, WI 53226, USA

Tel: +1-414-955-4493, Fax: +1-414-955-6361, E-mail: banerjee@mcw.edu

Financial support: This work was supported by National Institute of Health, Bethesda, Maryland, USA (Grant No. R01DK099201).

Conflicts of interest: None.

ORCID: Banani Banerjee, http://orcid.org/0000-0001-7552-1829. 
omy, ${ }^{6-8}$ and/or (2) common convergence of 2 visceral afferents onto the same spinal neuron (ie, viscero-visceral convergence). ${ }^{9,10}$ Animal models that induce a focal irritation or injury to the pelvis may produce cross-sensitization in the functionally comparable afferent pathways of the bowel and bladder. Accumulating evidences also suggest that chronic pelvic pain disorders, such as interstitial cystitis and IBS often overlap as a result of neuronal cross-talk via the convergence of pelvic afferents. ${ }^{11}$ With reports emerging about the involvement of various neurotransmitters, receptors and growth factors in the pathophysiology of visceral pain, a detailed understanding of the underlying molecular mechanism of visceral hypersensitivity is essential for the development of effective treatment and therapeutic strategies for the altered sensation in viscera of disorders such as interstitial cystitis, IBS, and ureteric colic.

MicroRNAs (miRNAs) are a class of endogenously expressed noncoding RNAs of 18-25 nucleotides and functionally distinct from but related to small interfering RNA (siRNAs). The mature single stranded miRNAs bind through complementary sequence homology to the 3'-untranslated region (UTR) of target mRNAs and cause a translational repression or mRNA degradation. ${ }^{12}$ Over the past decade, miRNAs have emerged as major transcriptional regulators of gene expression for critical biological processes including neuronal development, differentiation and synaptic plasticity in the central nervous system. At the molecular level, deregulation of several neurotransmitters, ion channels and proteins are reported to contribute to the development of central and peripheral sensitization and which is considered as the cause of chronic pain. ${ }^{13}$ Therefore, miRNA-mediated posttranscriptional regulation of protein and gene expression could also play a role in pain processing pathway. Indeed, several studies support the involvement of miRNA-mediated gene regulation in pathophysiology of acute and chronic pain. ${ }^{14}$ Involvement of miRNAs in inflammatory pain processing has been established recently in mice using conditional Dicer (miRNA synthesizing enzymes) deletion in Nav1.8 positive neurons. ${ }^{15}$ Effective strategies have been successfully used for RNA-based targeting in experimental models of neuropathic and inflammatory pain ${ }^{16}$ with particular reference to intrathecal (i.t.) administration of siRNA specific for $\mathrm{P}_{2} \mathrm{X}_{3}$ gene, ${ }^{17} \mu$-opioid receptors, ${ }^{18} \mathrm{~N}$-methyl-D-aspartate (NMDA) receptor subunit NR2B. ${ }^{19}$ Studies also indicate that certain miRNAs can specifically target neuronal mRNAs localized near the synapse and modulate input-specific synaptic protein synthesis and neuronal plasticity. ${ }^{20,21}$ However, the involvement of miRNA-mediated transcriptional regulation in visceral pain me- chanisms has not been clearly elucidated.

\section{Mechanism of MicroRNA Biogenesis}

In the nucleus, miRNA is transcribed as a long primary miRNA transcript (pri-miRNA) from miRNA gene by RNA polymerase II (Figure). This pri-miRNA is then processed into a stem loop structure of about 70-80 nucleotides known as precursor miRNA (pre-miRNA) by a microprocessor enzyme comprising of a double-strand (ds)-RNA-specific ribonuclease, Dorsha, along with its partner DGCR8 (DeGeorge syndrome critical region protein 8) also known as Pasha. ${ }^{22}$ This pre-miRNA is transported into the cytoplasm by exportin-5-RanGTP dependent mechanism. ${ }^{23}$ In the cytoplasm, pre-miRNA is digested by a second dsRNA-specific ribonuclease called Dicer into 18-25 nucleotide mature double-stranded miRNA with the help of TRBP (trans-activation response RNA binding protein) and Argonaute 2 (AgO2). ${ }^{24,25}$ The guide strand or mature miRNA is incorporated into a miRNA-induced silencing complex (miRISC), which carries the miRNA strand with sequence complementary to specific target mRNA. The RNA-induced silencing complex is the effector complex of the miRNA function and is comprised of miRNA, AgO2 proteins, and other RNA binding proteins. ${ }^{26,27}$

During biogenesis of miRNAs, loading of the guide strand into the miRISC makes it functional and ready to regulate posttranscriptional gene expression. The miRISC-mediated translational inhibition has been reported to arise from 3 putative mechanisms: (1) site specific cleavage, (2) enhanced mRNA decay, and (3) translational inhibition. The mechanism and the effectiveness of this regulation are dependent on the characteristics of the miRNA and target mRNA interaction. In metazoans, extensive base pairing has been demonstrated to induce mRNA cleavage, ${ }^{28,29}$ whereas, in mammals, imperfect binding leads to target repression through translational inhibition and/or mRNA destabilization. ${ }^{30}$ In addition, the location of complementary miRNA binding sites on the target mRNA plays an important role in determining the efficacy of the regulation. Although, binding of miRNA has been also demonstrated in the 5'UTR and open reading frame of $\mathrm{mRNA}$, these sites are less effective than those located in 3'UTR..$^{12,31-38}$ However, it has been shown that miRNA seeds in coding regions potentiate the effect of 3'UTRs and about a third of predicted miRNA-3'UTR interaction at the synapse also has been reported to involve at least one binding site in the coding region. ${ }^{39,40}$ Recently a link between miRNA- mediated poly (A)-tail length shortening and mRNA 


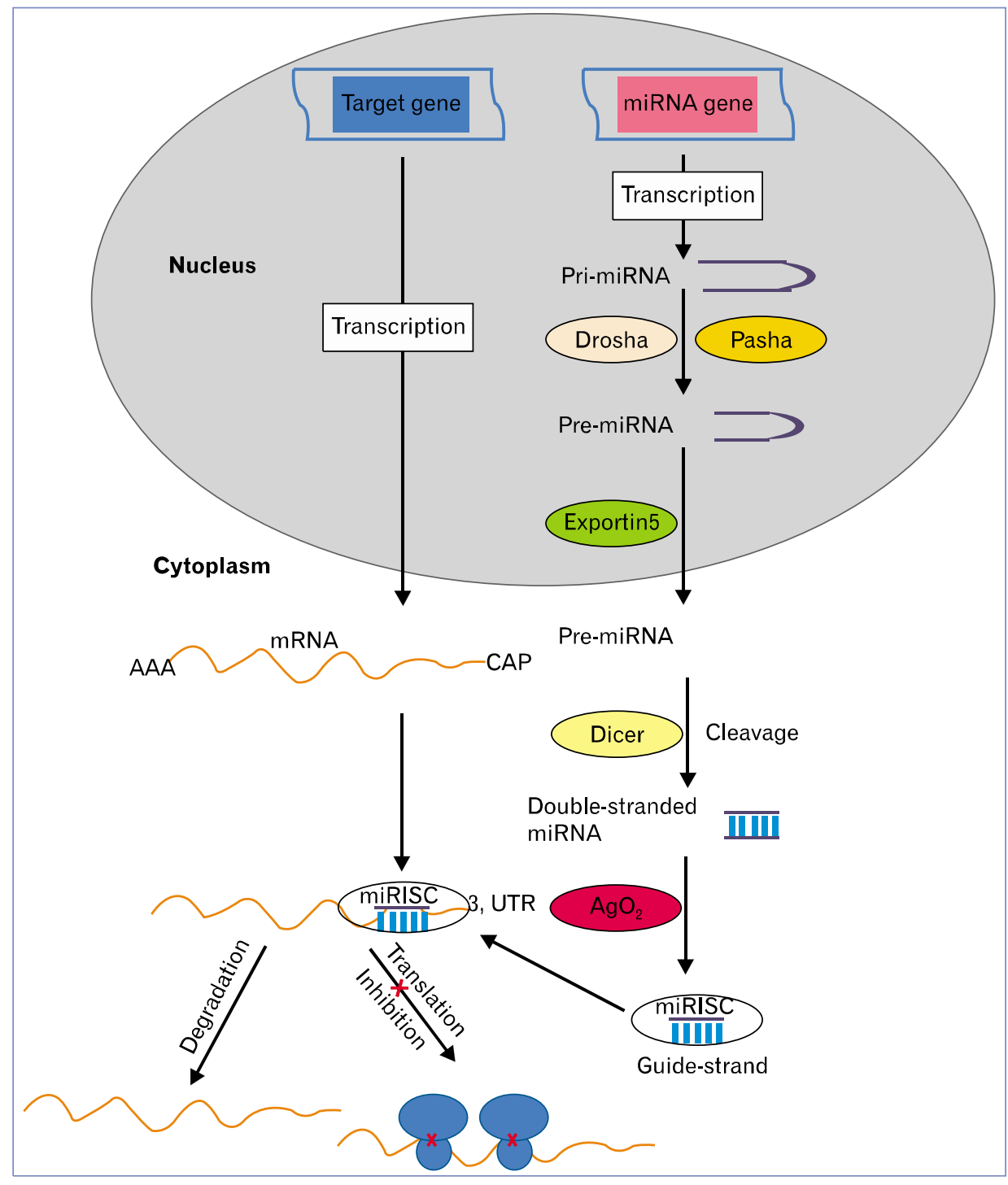

Figure. MicroRNA (miRNA) biogenesis pathway. In the nucleus, miRNAs are expressed as long hairpin RNAs called primiRNAs. Primary miRNAs (pri-miRNAs) are cleaved by Dorsha and Pasha into 70-100 nucleotides hairpin RNAs known as precursor miRNAs (pre-miRNAs). Precursor miRNAs are exported by expotin-5 to the cytoplasm, then another ribonuclease Dicer cleaves them into 18-25 nucleotides long mature double-stranded miRNA. The guide strand of the mature miRNA is then incorporated into a miRNA-induced silencing complex (miRISC). This complex binds to the 3'-UTR of the target gene through partial complementarity and prevents mRNA from translation into protein. If the miRNA carries the exact complementary sequence to an $\mathrm{mRNA}$, it will cleavage the target mRNA. destabilization has been reported, suggesting another potential mechanism of non-coding RNA-mediated gene regulation. ${ }^{41}$ Furthermore, the mRNAs under miRNA-mediated regulation are stored into cytoplasmic particles called processing bodies or glycine-tryptophan bodies. ${ }^{42}$ These cytoplasmic structures are free of translational machinery but are enriched in proteins that are required for mRNA inhibition. ${ }^{43}$

\section{Prediction and Validation of MicroRNA Targets}

The nucleotide sequences in the target mRNA that are engaged in miRNA binding are called the miRNA recognition element or seed region. ${ }^{26,44}$ The composition of this seed region var- ies but always involves a sequence with conserved Watson-Crick pairing (ie, the hydrogen bonding between guanine-cytosine and adenine-thymine) to the 5 ' region of the miRNA centered on nucleotides $2-7 .^{26}$ This includes canonical sites with a 6- to 8-nucleotide match between miRNA and mRNA, and noncanonical sites that include additional pairing at the 3'end of the miRNA. In addition, $\mathrm{AU}$ rich sites have been shown to increase the seed efficacy of miRNA binding.

Other factor includes the position of the seed within the 3'UTR of the target mRNA, with sites at the ends of the 3'UTR being more accessible than those in the middle because long 3'UTRs may form occlusive interactions and this factor greatly reduces miRNA site accessibility. In addition, the presence of multiple sites for the same or different miRNAs on the target 
mRNA increases the miRNA-mediated repression response of the target gene. Moreover, cooperative regulation, where the seed sequences are within 40 nucleotide but with a minimum of 8-nucleotide gap results in stronger repression than the sum of the individual and independent sites. ${ }^{45}$ MicroRNA cooperativity is defined as the positive interaction of two or more individual miRNAs, or one individual miRNA acting on multiple seed regions on the same 3'UTR for target repression. In this context, miRNA cooperatively studies on neuronal system demonstrate that, miRNA seed density in synaptic mRNAs is higher than in non-synaptic mRNAs, indicating that synaptic mRNAs may be under stronger miRNA control. Therefore, miRNA cooperativity could be a relevant mechanism in the regulation of synaptic mRNA expression. miRNA silencing efficiency is also regulated by the cellular concentrations and stoichiometric relationships between: (1) the miRNAs, (2) the target mRNAs, and (3) the RISC complexes. MicroRNAs that have multiple targets and are highly expressed are supposed to downregulate individual target mRNAs to a lesser extent than those with a lower number of targets. In addition, highly abundant target transcripts that may act as decoys, dilute the effect of miRNAs under specific conditions. $^{46}$

The manual prediction of miRNA: mRNA interaction is not feasible because of the large and growing number of miRNA species and the enormous number of putative target mRNAs. Computational analysis using algorithms and prediction databases is the common method to identify miRNA targets. Several databases such as TargetScan, miRWalk, miRanda, PICTAR5, and pathway analysis using Ingenuity Software have been utilized to analyze the potential target genes for miRNAs. The target prediction programs are based on seed region recognition tools that basically list all the sites with miRNA-binding properties and rank them accordingly to the kind of seed, conservation across evolution and some of the above mentioned factors known to modulate binding site efficiency. ${ }^{47}$ However, despite the advancement of prediction bioinformatics, the percentage of predicted targets that fulfill the experimental validation is not optimal. In line with this observation, recent data suggest that miRNA-target interaction also involves the 3' end of miRNAs and some of these interactions are functional. ${ }^{48}$ There are other parameters that are not taken into consideration in this target prediction algorithms could also influence the target site accessibility and its regulation, for instance, the secondary structure of miRNA and its association with RNA binding proteins (RBPs). ${ }^{49}$ Several approaches have been used to validate functional interaction be- tween miRNAs and their predicted mRNA targets. The reporter construct carrying the binding site of putative mRNA under the control of luciferase promoter has been used extensively in heterologous in vitro systems to validate a functional interaction between a particular miRNA and its predicted targets. Alternatively, single-stranded modified RNA oligos (referred to as miRNA target protectors) that specifically blocked the interaction of a given miRNA with its target mRNA has been used in several in vitro studies. ${ }^{50,51}$ Recently, plasmid-based target protectors have been developed to specifically block the miRNA silencing activity in mammalian system, which may have wide application in miRNA target identification. ${ }^{52}$

\section{Involvement of MicroRNA in Neuronal Activity}

Several miRNAs are developmentally regulated and demonstrate tissue-specific expression patterns, including many of them expressed only in the nervous system. These miRNAs may play major roles both in neuronal development and neuronal functions. Recent studies emphasize the involvement of miRNAs and their target genes in neuronal development, from early neurogenesis and cell-fate specification to neuronal differentiation and synaptic development of postmitotic neurons. ${ }^{53}$ In the mature neurons, miRNAs are important for maintaining normal neuronal function. ${ }^{21,54-57}$ During activity-dependent synaptic plasticity, a single synapse or sets of synapses undergo intense modification in an independent manner for a long period of time. ${ }^{58}$ Therefore, local posttranscriptional modification regulated by activity is an important event for the plasticity and maintenance of neuronal connections. ${ }^{59-61}$ Experimental evidence demonstrates the presence of specific mRNAs and other translational machineries such as ribosomes and non-coding RNAs at the dendritic regions of the neurons, where they are likely to involve in local protein translation. ${ }^{62,63}$ Moreover, some mRNAs are located at the postsynaptic density (PSD) as polyribosome structures and encode proteins such as kinases, which are essential components to mediate synaptic plasticity. ${ }^{62}$ Therefore, local translation mechanism could play a major role in synaptic plasticity and certainly contribute to the molecular basis of learning and memory.

MicroRNAs are enriched in the brain and there is evidence of their involvement in local protein synthesis at the synaptic level. ${ }^{64-67}$ Several components of the miRNA biogenesis pathway and translation inhibitory machinery have been identified in the isolated synapto-neurosomes, ${ }^{68}$ and studies indicate that miRNA 
driven posttranscriptional regulation locally at the synapse can either increase or decrease mRNA translation through different mechanisms during synaptic activity and stimulation. In addition to their involvement in physiological conditions, recent studies suggest that miRNAs also play an important role in the pathophysiological mechanisms of neurological diseases such as Parkinson's, Alzheimer's and Huntington's disease and Tourette syndrome. ${ }^{69,70}$

One of first studies reporting the control of local translation by miRNA at the synapses showed that miR-134 negatively regulates LIMK1 in an activity-dependent manner. ${ }^{71}$ LIMK1 is a protein kinase that controls actin filament polymerization through inhibition of actin depolymerization factor cofilin. ${ }^{71}$ This regulation could be critical for synaptic transmission and plasticity since majority of the excitatory synapses are formed on denderitic spines, which are actin-rich protrusions from the dendritic shaft. $^{72,73}$ Over-expression of miR-134 inhibits local translation of LIMK1 mRNA at the synapse resulting in a negative regulation of the size of the dendritic spines. Involvement of miR-132 as an activity-modulated miRNA has been established in a recent study, where bicuculline-mediated blockages of GABAA inhibitory tone in neurons resulted in a rapid increase in the expression of miR-132 precursor and mature miR-132. ${ }^{74}$ Furthermore, this regulation could be attenuated by pretreatment with the selective NMDA receptor antagonist amino-5-phosphonovaleric acid. The involvement of miR-132 in different neuronal activities is evident from the findings that inhibitors for $\mathrm{CaM}$ kinase, mitogen activated protein kinase-extracellular signal-regulated kinase (MEK-ERK) or cAMP response element binding protein (CREB), all prevent miR-132 upregulation upon activity enhancement, suggesting that miR-132 is predominantly regulated by these signaling pathways. MicroRNA-132 directly targets p250GAP, a protein known to inhibit Rho family GTPases. ${ }^{75,76}$ Overall, miRNA upregulation modulates dendritic morphogenesis and

Table. Involvement of MicroRNAs in Synaptic Plasticity and Pain Mechanisms

\begin{tabular}{|c|c|c|c|c|c|c|c|}
\hline miRNA & $\begin{array}{l}\text { Synaptic plasticity } \\
\text { models/conditions }\end{array}$ & Tissue & References & miRNA & $\begin{array}{l}\text { Pain models/ } \\
\text { conditions }\end{array}$ & Tissue & References \\
\hline $\operatorname{miR}-134$ & BDNF exposure & $\begin{array}{l}\text { Hippocampal } \\
\text { neuron }\end{array}$ & 71 & $\begin{array}{l}\text { miRNA-183, }-182,-96,-71 \\
-125 b,-30 d,-379,-103\end{array}$ & SNL & DRGs/SDH & $105-109$ \\
\hline miR-132 & Bicuculline $/ \mathrm{KCl}$ & $\begin{array}{l}\text { Hippocampal } \\
\text { neuron }\end{array}$ & 74 & $\begin{array}{l}\text { miRNA-1, }-124,-129-1 / 2, \\
-223,-124 a,-21,-137 \\
-181 \mathrm{a},-219, \text { and others }\end{array}$ & SCI & $\mathrm{SC} / \mathrm{SDH}$ & $\begin{array}{l}110,112 \\
117\end{array}$ \\
\hline miR-219 & NMDA antagonist & $\begin{array}{l}\text { Prefrontal cortex/ } \\
\text { hippocampus }\end{array}$ & 81 & $\begin{array}{l}\text { miR-96, -146a, -34c, }-125 b \text {, } \\
\text {-103, Let-7 family }\end{array}$ & $\mathrm{CCI}$ & $\begin{array}{l}\text { DRGs/ } \\
\text { Hippocampus }\end{array}$ & 111,113 \\
\hline miR-181a & $\begin{array}{l}\text { Cocaine/ } \\
\text { Amphetamines }\end{array}$ & $\begin{array}{l}\text { Hippocampal } \\
\text { neuron }\end{array}$ & 21 & $\begin{array}{l}\text { miR-29b, }-142,-424,-223 \\
-21,-221,-182,-183,-145 \\
\text { and others }\end{array}$ & $\mathrm{SNC}$ & Sciatic nerves & 122 \\
\hline miR-188 & LTP & Hippocampus & 56 & miR-1, -16, -206 & SNA & DRG/SDH & 115 \\
\hline miR-125b, -132 & FNMRP & $\begin{array}{l}\text { Mouse brain/ } \\
\text { neuron }\end{array}$ & 55 & miR-21, -143 & SNT & DRGs & 119,120 \\
\hline miR-124 & miRNA depletion & $\begin{array}{l}\text { Retinal ganglion } \\
\text { cell }\end{array}$ & 78 & miR-200b, -429 & PNL & Nucleus & 114 \\
\hline $\mathrm{miR}-29 \mathrm{a} / \mathrm{b}$ & Psychoactive drugs & $\begin{array}{l}\text { Brain regions/ } \\
\text { neurons }\end{array}$ & 82 & & & Accumbens & \\
\hline \multirow[t]{2}{*}{$\begin{array}{l}\operatorname{miR}-124,-181 \mathrm{a}, \\
\text { Let-7d }\end{array}$} & Cocaine & Necleous & 79 & $\begin{array}{l}\text { miR-183, }-124 a,-134,-143 \\
-1,-16,-206\end{array}$ & CFA & DRGs/SDH & $\begin{array}{l}87,115,118, \\
120\end{array}$ \\
\hline & & Accumbens & & miR-124a & $\begin{array}{l}\text { Formalin/ } \\
\text { IL-1 } \beta\end{array}$ & $\begin{array}{l}\text { SDH/spinal } \\
\text { microglia }\end{array}$ & 116,121 \\
\hline \multirow[t]{3}{*}{ miR-212 } & Cocane & Dorsal Striatum & 80 & miR-181a & Cystitis & $\mathrm{SDH}$ & 103 \\
\hline & & & & $\begin{array}{l}\operatorname{miR}-449 b,-500,-320 \\
-199 a-5 p\end{array}$ & BPS & Bladder/cell culture & 100,101 \\
\hline & & & & $\operatorname{miR}-29 a$ & IBS & $\begin{array}{l}\text { Colon/small bowel/ } \\
\text { cell culture }\end{array}$ & 99 \\
\hline
\end{tabular}

miRNA, microRNA; BDNF, brain-derived neurotrophic factor; NMDA, N-methyl-D-aspartate; LTP, long-term potentiation; FMRP, fragile x mental retardation protein; SNL, spinal nerve ligation; DRG, dosal root ganglion; SDH, spinal dorsal horn; SCI, spinal cord injury; SC, spinal cord; CCI, chronic constriction injury; SNC, sciatic nerve crush; SNA, sciatic nerve transactivation; SNT, sciatic nerve transaction; PNL, partial nerve ligation; CFA, complete Freund's adjuvant; BPS, bladder pain syndrome; IBS, irritable bowel syndrome. 
spinogenesis. ${ }^{77}$ Several major miRNAs involved in synaptic plasticity are listed in Table. ${ }^{21,55,56,71,74,78-82}$

\section{Activity-dependent Regulation of MicroRNAs in Pain Processing}

In pain mechanism, selected miRNAs have been implicated in multiple cellular processes, including neuronal plasticity and neurogenesis, nociceptor excitability and chronic pain condition. A recent study proposed brain derived nerve growth factor (BDNF)-driven upregulation of miR-132 in cortical neurons. ${ }^{83}$ Since BDNF is recently identified as a modulator of nociception, it is conceivable that BDNF-induced upregulation of miR-132 would increase dendritic morphogenesis and arborization in the nociceptive pathway, resulting in an increase in pain signal transmission. The role of miRNAs in dendritic spine remodeling and synaptic plasticity has been documented by Lippi et al. ${ }^{82}$ In this study adults mice exposed to psychoactive drugs like nicotine or cocaine demonstrated over-expression of miR-29a/b consistently in different brain regions. The protein Arpc 3 involved in actin branching during dendritic spine maturation was identified as the target for miR-29a/b, suggesting that these miRNAs regulate the activity-dependent structural plasticity associated with psychoactive exposures. Several studies identified a deregulation of miR-29a/b in pain conditions such as in spinal dorsal horn-induced muscle inflammation, complex regional pain syndrome (CRPS), and chronic constriction injury. ${ }^{84,85}$ However, the target proteins of miR-29a/b and their subsequent regulatory mechanisms in pain processing are not clearly defined.

One of the first demonstrations of the role of miRNAs in chronic pain came from the study by Zhao et al, ${ }^{15}$ where conditional knockout of Dicer (enzyme essential for mature miRNA synthesis) in Nav1-8-positive nociceptors in the dorsal root ganglia (DRG) resulted in significant attenuation of inflammatory pain. This finding suggests that miRNAs-mediated regulation of this subpopulation of sensory neurons is necessary for inflammation-induced chronic pain condition. The direct targeting of miRNA let-7 on mu opioid receptors during opioid tolerance clearly emphasizes an integral role of miRNA-mediated regulation in chronic pain. ${ }^{86}$ In an inflammatory rat model of CFA-induced muscle pain, several miRNAs including miRs-10a, $-29 a$, $-98,-99 a,-124 a,-134$, and -183 were significantly downregulated in neurons of the ipsilateral trigeminal ganglion. ${ }^{87}$ This downregulation of specific miRNAs was considered to increase the expression of several "pain-related" proteins and therefore, fa- cilitated the development of inflammation and allodynia. On the other hand, upregulation of miR-155 and miR-223 in the prefrontal cortex has been reported following carrageenan-induced facial inflammation in mice. This study also demonstrated an inverse relationship between miR-155 and one of its potential targets, the transcription factor, CCAAT/enhancer binding protein $\beta$ in this inflammation model. ${ }^{88}$ In a murine peritonitis model of self-limiting acute inflammation, increased levels of miRs (-21, $-146 \mathrm{~b}, 208 \mathrm{a},-203,-142,-302 \mathrm{~d}$, and -219) could be counter-regulated by administration of resolvin D1, an anti-inflammatory lipid mediator. ${ }^{89}$ Since resolvin D1 has been reported as an important mediator of anti-inflammatory and anti-nociceptive behaviors, this finding indicates that specific miRNAs are the posttranscriptional regulators of the inflammatory pain condition. ${ }^{90}$ In the neuropathic pain models, a downregulation of miR-181a or other members of the miR-181 family, namely miR-181b/c/d has been documented. ${ }^{91,92}$ In this context, deregulation of miR-181a expression in various brain regions has been reported following chronic exposure to drug of abuse. ${ }^{21}$

\section{MicroRNAs as Modulators of Neuro-immune System}

Noxious stimulations have been reported to deregulate the expression of miRNAs in pain circuitry from primary afferents to brain regions associated with emotional components of pain perception. Several miRNAs (termed as NeurimmiRs) such as miR-124 and miR-132 can act within both the nervous and immune systems by primarily targeting several transcription factors and other regulatory genes which may simultaneously modulate both immune and neuronal processes through alterations of neuron-glia or brain-peripheral signaling. ${ }^{93}$ These findings indicate that miRNAs control multiple cellular pathways by regulating multiple gene products including several cellular enzymes, trophic factors, neurotransmitters, ion channels, many of them are individually studied as drug targets. miRNAs are frequently deregulated and differentially expressed in disease tissues with neurogenic pain such as in CRPS. ${ }^{85}$ The deficiency of anti-inflammatory cytokines in patients with CRPS and the beneficial effect of therapy with glucocorticoids support the association between pathohysiological mechanisms and neuro-immune dysfunction. ${ }^{94}$ Various studies also identified the mediators of neuroinflammation as critical component of diabetic neuropathy, ${ }^{95}$ in addition to cellular mechanisms that include the classical changes of the diabetic milieu. ${ }^{96}$ Besides the role of intracellular miRNAs 
as the posttranscriptional regulator of gene expression, the role of extracellular miRNAs as signal regulators for membrane receptors activation have recently been established. ${ }^{97}$ The extracellular miRNA-let-7 is identified as an activator of Toll like receptor (TLR)-7 in both immune cells and neurons. In line with this finding, an unconventional role of extracellular miRNAs for rapid excitation of nociceptor neurons via TLR7 has been proposed. ${ }^{98}$ Here, miRNA-let-7b induces rapid inward currents and action potentials in DRG only in neurons coexpressing TLR7 and transient receptor potential ankyrin 1 (TRPA1) ion channel, and are abolished in mice lacking $T l r 7$ or Trpa1. Furthermore, let-7b induces TLR7/TRPA1-dependent single-channel activities in DRG neurons and HEK293 cells overexpressing TLR7/TRPA1 and let-7b inhibitor reduces formalin-induced TRPA1 currents and spontaneous pain in vivo system. Therefore, secreted extracellular miRNAs may also serve as novel pain mediators via activating TLR7/TRPA1 in nociceptor neurons. $^{98}$

\section{MicroRNAs in Visceral Pain}

After tissue injury, changes in several neurotransmitters, ion channels, and proteins contribute to the development of central and peripheral sensitization, which is considered as the cause of chronic pain. ${ }^{13}$ Since miRNAs are the posttranscriptional regulators of protein and gene expression, it is possible that miRNAmediated deregulation of these molecules both peripherally and centrally also contribute to the visceral hypersensitivity and pain processing in disorders such as interstitial cystitis, IBS and bladder pain syndrome. In a recent study, an increase in miR-29a in colon tissues and blood microvesicles of patients with IBS has been correlated with increased intestinal membrane permeability. ${ }^{99}$ Authors further demonstrated that miR-29a interact with complementary binding sites at the 3'UTR of the glutamate ammonia ligase gene and that leads to downregulation of glutamine synthase expression and increased intestinal permeability and eventually results in chronic visceral pain. In another study, increased in expression of several miRNAs namely miR-328, miR-320, miR-449b, and miR-500 was directly correlated with the down regulation of neurokinin-1 (NK1) receptors in the bladder biopsies from BPS patients. ${ }^{100}$ Using cell-based models, authors showed that prolonged exposure of NK1 receptors to substance $\mathrm{P}$ caused a decrease in NK1 receptor mRNA expression and a concomitant increase of regulatory miRNAs $-449 \mathrm{~b}$ and -500 . This modulation of NK1 receptors by miRNAs may be the underlying molecular mechanism of increased urothelial permeability and painful bladder syndrome in BPS patients. Monastyrskaya et al also documented a possible link between miR-199a-5p and the control of urothelial permeability in bladder pain syndrome. ${ }^{101}$ In urothelial cells, overexpression of miR-199a demonstrated impairment in tight junction formation resulting in increased epithelial permeability. Differences in miRNAs expression have also been reported in endometrium between patients with and without painful endometriosis. ${ }^{102}$ A recent study from our lab established the involvement of miRNA-mediated post-transcriptional regulation of the developing spinal GABAergic system following neonatally-induced cystitis in rats. ${ }^{103}$ Cystitis was developed neonatally by intravesicular injection of zymosan into the bladder during postnatal $(\mathrm{P})$ days $\mathrm{P} 14-\mathrm{P} 16$. A significant upregulation of mature miR-181a in the L6-S1 spinal dorsal horns was observed in cystitis rats. The target gene analysis demonstrated multiple complementary binding sites in miR-181a for the $\mathrm{GABA}_{\mathrm{A}}$ receptor subunit $\mathrm{GABA}_{\mathrm{A} \alpha-1}$. An increase in miR-181a concomitantly resulted in long-term downregulation of spinal $\mathrm{GABA}_{\mathrm{A} \alpha-1}$ receptor subunit gene and protein expression in spinal dorsal horns of adults rats following neonatally-induced cystitis. These findings indicate that miRNA-mediated transcriptional deregulation of spinal gene expression may contribute to the visceral sensitization of patients with chronic cystitis. Using bioinformatics, Zhao et $\mathrm{al}^{104}$ demonstrated that miR-181a indeed carries complementary binding sites for the 3'UTR region of the $\mathrm{GABA}_{A \alpha-1}$ gene. They further verified miR-181, miR-216 and miR-203 as the target miRNAs for $\mathrm{GABA}_{\mathrm{A \alpha}-1}$ gene using luciferase reporter assay. We recently investigated the involvement of miRNAs in long-term cortical plasticity following esophageal acid exposure in rats neonatally from P7 to P14 (our unpublished findings). The miRNA expression in cortical synaptoneurosomes was examined using next generation sequencing and quantitative real time PCR in adult rats on P60. Three miRNAs -29b, -34a, and $-30 \mathrm{a}$ exhibited significant upregulation in acid-treated rats compared to saline-treated controls. This finding strongly suggests the involvement of miRNAs in long-term cortical plasticity following esophageal acid exposure early in life. Here, we review specific miRNAs that have been identified as the regulators of nociceptive activity and highlight their possible association with pain processing in various pain conditions (Table ${ }^{87,99,100,101,103,105-122}$ ). 


\section{Cognitive and Behavioral Components of Pain Mechanism}

Brain specific miRNAs are emerging as regulators of cognition, neuronal plasticity, and memory by regulating $\mathrm{mRNAs}$ that are associated with synaptic structure and function. A set of specific miRNAs not only control cognition and emotional processes but also neuro-immune communication in the brain. ${ }^{93,123}$ Moreover, specific regions in the brain are actively involved in pain perception and behavior in humans and rodents and structural brain changes are associated with sensory and emotional function in long-term neuropathic pain in rodent. ${ }^{124}$ The abnormalities in hippocampus volume are observed in human CRPS and in mouse with speared nerve injury. Similar to CRPS in humans, speared nerve injury mice exhibit increased anxiety like behavior and abnormal contextual fear extinction and this is associated with reduced ERK kinase expression, decrease neurogenesis and altered synaptic plasticity. ${ }^{125}$ Dopaminergic and glutametergic inputs from amygdala, hippocampus and prefrontal cortex to the nucleus accumbens have been reported to involve in the emotional control circuits and recent human studies documented the role of nucleus accumbens in the emotional aspects of pain processing. ${ }^{126}$ Moreover, miRNA-mediated transcriptional deregulation has been linked with the emotional dysfunction and maladaptive responses of nucleus accumbens in chronic pain condition associated with neuropathic pain. ${ }^{114}$

\section{Genetic Polymorphisms and Pain Condition}

Altered miRNA expression is usually a consequence of genetic mutation which may also cause loss or gain of function. ${ }^{127}$ However, the functional consequences of polymorphisms in miRNA genes and/or their targets, and the mechanisms by which miRNAs regulate pain circuitries and modulate nociception are not yet clearly defined. Several meta-analyses are available of the genetics of pain and associated specific loss or gain of function polymorphisms with altered pain perception. ${ }^{128}$ Although, single nucleotide polymorphisms (SNPs) are less common in miRNAs and their target binding sites, several of the SNPs in miRNAs that are bioinformatically predicted to be associated with pathogenesis are also experimentally verified. ${ }^{129}$ These SNPs can affect the expression of a large number of genes when the production of the miRNAs is influenced by those particular SNPs. Similarly,
SNPs in target sites of miRNAs can either modulate or disrupt existing binding sites and create new binding sites for the miRNAs. These polymorphisms may further influence gene expression and the pathogenic mechanisms in disease development. ${ }^{130}$

\section{Role of MicroRNAs as Novel Biomarkers}

Recent studies have suggested that miRNAs are promising biomarkers for a number of disorders including cancer, heart failure, and neurodegenerative disorders. Circulating miRNAs are release in serum and cerebrospinal fluid from cells through an endocytic pathway, and are packed into exosomes vesicles in the circulation. These secreted miRNAs in exosomes and in other microvesicle are protected from endonuclease-dependent degradation and reported to influence cellular microenvironment of immune and endothelial systems. ${ }^{131}$ In addition, unlike serum miRNAs, exosome-entrapped miRNAs are capable of crossing the blood brain barrier (BBB). ${ }^{132}$ Inflammatory processes are also activated in the spinal cord upon peripheral nerve injury and involved microglia activation and leakage at the blood nerve barrier along the entire neuraxis. ${ }^{133}$ The leakage of the blood-nerve barrier or blood-spinal barrier is emerging in pathophysiology of neuropathic pain accompanied with changes in tight junction proteins. ${ }^{134}$ Moreover, studies also indicate that a number of neurological diseases are associated with $\mathrm{BBB}$ dysfunction resulting in elevated barrier permeability and leakage of molecules such as miRNAs in and out of the brain. ${ }^{134}$ Interestingly, miR-132 blood level was reported to alter significantly in patients with CRPS, a disabling chronic neuropathic pain affecting one or more extremities. ${ }^{85}$

\section{MicroRNAs as Therapeutic Targets for the Treatment of Chronic Pain}

In recent years, several strategies have been put forward to target miRNAs expression in pain management and treatment. In direct strategies, the use of oligonucleotides directly or virus-based constructs to either block the over-expression of miRNAs or to substitute for the loss of expression of miRNAs have been proposed. The indirect strategies involve the use of drugs to modulate miRNA expression by regulating their transcription and processing. For overexpressing miRNAs, miRNA mimics comprising the nucleotide sequences of either pre-miRNAs or mature miRNAs have been developed, whereas, miRNA inhibition utilizes the use of anti-sense oligos (anti-miRNAs), 
miRNA sponges, or miRNA decoys. ${ }^{135,136}$ MicroRNA decoys enable long-term suppression of miRNA expression by using nuclease resistant complementary RNAs expressed in viral vectors that harbor RNA expression cassettes driven under RNA polymerase II. ${ }^{136}$ Antisense oligos function as competitive inhibitors by annealing to the mature miRNA guide strand and inducing degradation or stoichiometric duplex formation. miRNA sponges are designed as longer RNA molecules carrying several miRNA complementary sequences for simultaneously inhibiting several miRNAs.

A major challenge for the delivery of miRNAs into central nervous system is the blood brain barrier, the natural barrier hindering the access of miRNAs to the central nervous system. Some effective approaches for gene silencing in the central nervous system are: lentiviral-vector-mediated delivery; germline transfection and stereotaxic application. ${ }^{137,138}$ Another specific approach is to incorporate cholesterol molecules to the sense strand and making it accessible to cells with high density lipoprotein receptors such as oligodendrocytes in the brain. ${ }^{14}$ The further advancement in small RNA delivery technique is the development of immunoliposome, the complex of a receptor-directed monoclonal antibody, liposomes and small hairpin RNA expression plasmids. The targeted delivery with immunoliposomes facilitates the conjugated RNA to cross the BBB and reach specific regions in the brain. In the context of chronic pain, intrathecal administration of miR-124 showed an anti-nociceptive effect in both inflammatory and nerve injury-induced pain models. Furthermore, kynast et al showed that the intravenous injection of miR-124 alleviates the nociceptive response to formalin test and identified methyl $\mathrm{CpG}$ binding protein $2(\mathrm{MeCP} 2)$ as the target. $\mathrm{MeCP} 2$ is an epigenetic modulator of $\mathrm{BDNF}$, one of the major players in inflammatory pain mechanisms. ${ }^{116}$ An example of multiple targeting by a single miRNA has been documented for the subunits of voltage-gated calcium channel. MicroRNA-103 simultaneously regulates the expression of three subunits of Cav1.2-comprising L-type calcium channel (Cav1.2-LTC) in an integrative manner. In functional study, it has been shown that miR-103 knockdown in naïve rats result in hypersensitivity to pain. Moreover, in neuropathic pain there was a down regulation of miR-103 and intrathecal application successfully relieved pain, thus identifying miR-103 as a possible therapeutic target in neuropathic chronic pain. ${ }^{107}$ However, not much information is available on the application of miRNA-based targeting strategies for the treatment and management of visceral pain.

\section{Conclusion and Future Strategies}

The regulatory role of miRNAs in the modulation of pain pathway has been extensively studied in the past decade and accumulating evidence implicates miRNAs as potential targets for the treatment of chronic pain. Several studies have identified differentially expressed miRNAs in specific visceral organs following nociceptive stimuli in experimental animals and also in colon and bladder biopsies from patients with IBS and BPS. However, comprehensive studies elucidating the miRNA-mediated deregulation at the level of viscera as well as the changes at the DRG and spinal levels that innervate visceral organs are still lacking. Future research should focus on answering several important questions such as (1) whether a single gene is regulated by multiple miRNAs or a single miRNA is targeting several genes those are involved in a common downstream signaling process in a tissue specific manner; (2) are there specific miRNAs and their target genes that are differentially expressed in visceral organs such as in bladder and colonic myenteric plexus as well as in DRGs and spinal dorsal horn regions innervating these organs. This information will certainly enable us to delineate the underlying molecular mechanisms of the chronic pelvic neuroplasticity and cross-organ sensitization and facilitates the development of miRNA-based therapeutic strategies for the treatment of visceral pain.

\section{References}

1. Giamberardino MA, Berkley KJ, Affaitati G, et al. Influence of endometriosis on pain behaviors and muscle hyperalgesia induced by a ureteral calculosis in female rats. Pain 2002;95:247-257.

2. Terruzzi V, Magatti F, Quadri G, Tenore C, Minoli G, Belloni C. Bladder dysfunction and irritable bowel syndrome. Am J Gastroenterol 1992;87:1231-1232.

3. Whorwell PJ, Lupton EW, Erduran D, Wilson K. Bladder smooth muscle dysfunction in patients with irritable bowel syndrome. Gut 1986;27:1014-1017.

4. Lowenstein L, Kenton K, Mueller ER, et al. Patients with painful bladder syndrome have altered response to thermal stimuli and catastrophic reaction to painful experiences. Neurourol Urodyn 2009; 28:400-404.

5. Warren JW, Morozov V, Howard FM. Could chronic pelvic pain be a functional somatic syndrome? Am J Obstet Gynecol 2011;205: 199, e1-e5.

6. Christianson JA, Liang R, Ustinova EE, Davis BM, Fraser MO, Pezzone MA. Convergence of bladder and colon sensory innervation occurs at the primary afferent level. Pain 2007;128:235-243.

7. Malykhina AP. Neural mechanisms of pelvic organ cross- sensitiza- 
tion. Neuroscience 2007;149:660-672.

8. Malykhina AP, Qin C, Greenwood-van Meerveld B, Foreman RD, Lupu F, Akbarali HI. Hyperexcitability of convergent colon and bladder dorsal root ganglion neurons after colonic inflammation: mechanism for pelvic organ cross-talk. Neurogastroenterol Motil 2006;18:936-948.

9. Qin C, Foreman RD. Viscerovisceral convergence of urinary bladder and colorectal inputs to lumbosacral spinal neurons in rats. Neuroreport 2004;15:467-471.

10. Qin C, Malykhina AP, Akbarali HI, Foreman RD. Cross-organ sensitization of lumbosacral spinal neurons receiving urinary bladder input in rats with inflamed colon. Gastroenterology 2005;129: 1967-1978.

11. Pezzone MA, Liang R, Fraser MO. A model of neural cross-talk and irritation in the pelvis: implications for the overlap of chronic pelvic pain disorders. Gastroenterology 2005;128:1953-1964.

12. Farh KK, Grimson A, Jan C, et al. The widespread impact of mammalian MicroRNAs on mRNA repression and evolution. Science 2005;310:1817-1821.

13. Ji RR, Kohno T, Moore KA, Woolf CJ. Central sensitization and LTP: do pain and memory share similar mechanisms? Trends Neurosci 2003;26:696-705.

14. Tan PH, Pao YY, Cheng JK, Hung KC, Liu CC. MicroRNAbased therapy in pain medicine: Current progress and future prospects. Acta Anaesthesiol Taiwan 2013;51:171-176.

15. Zhao J, Lee MC, Momin A, et al. Small RNAs control sodium channel expression, nociceptor excitability, and pain thresholds. J Neurosci 2010;30:10860-10871.

16. Niederberger E, Kynast K, Lotsch J, Geisslinger G. MicroRNAs as new players in the pain game. Pain 2011;152:1455-1458

17. Dorn G, Patel S, Wotherspoon G, et al. siRNA relieves chronic neuropathic pain. Nucleic Acids Res 2004;32:e49. Epub 2004/03/18.

18. Luo MC, Zhang DQ, Ma SW, et al. An efficient intrathecal delivery of small interfering RNA to the spinal cord and peripheral neurons. Mol Pain 2005;1:29.

19. Tan PH, Yang LC, Shih HC, Lan KC, Cheng JT. Gene knockdown with intrathecal siRNA of NMDA receptor NR2B subunit reduces formalin-induced nociception in the rat. Gene Ther 2005;12:59-66.

20. Pichardo-Casas I, Goff LA, Swerdel MR, et al. Expression profiling of synaptic microRNAs from the adult rat brain identifies regional differences and seizure-induced dynamic modulation. Brain Res 2012;1436:20-33.

21. Saba R, Störchel PH, Aksoy-Aksel A, et al. Dopamine-regulated microRNA MiR-181a controls GluA2 surface expression in hippocampal neurons. Mol Cell Biol 2012;32:619-632.

22. Han J, Lee Y, Yeom KH, et al. Molecular basis for the recognition of primary microRNAs by the Drosha-DGCR8 complex. Cell 2006;125:887-901.

23. Bohnsack MT, Czaplinski K, Gorlich D. Exportin 5 is a RanGTPdependent dsRNA-binding protein that mediates nuclear export of pre-miRNAs. RNA 2004;10:185-191.

24. Chendrimada TP, Gregory RI, Kumaraswamy E, et al. TRBP recruits the Dicer complex to Ago2 for microRNA processing and gene silencing. Nature 2005;436:740-744.

25. Meister G, Tuschl T. Mechanisms of gene silencing by dou- ble-stranded RNA. Nature 2004;431:343-349.

26. Bartel DP. MicroRNAs: target recognition and regulatory functions. Cell 2009; 136:215-233.

27. Hutvagner G, Zamore PD. A microRNA in a multiple-turnover RNAi enzyme complex. Science 2002;297:2056-2060.

28. Rhoades MW, Reinhart BJ, Lim LP, Burge CB, Bartel B, Bartel DP. Prediction of plant microRNA targets. Cell 2002;110:513520 .

29. Yekta S, Shih IH, Bartel DP. MicroRNA-directed cleavage of HOXB8 mRNA. Science 2004;304:594-596. Epub 2004/04/24.

30. Fabian MR, Sonenberg N, Filipowicz W. Regulation of mRNA translation and stability by microRNAs. Annu Rev Biochem 2010; 79:351-379.

31. Chi SW, Zang JB, Mele A, Darnell RB. Argonaute HITS-CLIP decodes microRNA-mRNA interaction maps. Nature 2009;460: 479-486.

32. Easow G, Teleman AA, Cohen SM. Isolation of microRNA targets by miRNP immunopurification. RNA 2007;13:1198-1204.

33. Grimson A, Farh KK, Johnston WK, Garrett-Engele P, Lim LP, Bartel DP. MicroRNA targeting specificity in mammals: determinants beyond seed pairing. Mol Cell 2007;27:91-105.

34. Leung AK, Vyas S, Rood JE, Bhutkar A, Sharp PA, Chang P. Poly(ADP-ribose) regulates stress responses and microRNA activity in the cytoplasm. Mol Cell 2011;42:489-499.

35. Lewis BP, Burge CB, Bartel DP. Conserved seed pairing, often flanked by adenosines, indicates that thousands of human genes are microRNA targets. Cell 2005;120:15-20.

36. Lim LP, Lau NC, Garrett-Engele P, et al. Microarray analysis shows that some microRNAs downregulate large numbers of target mRNAs. Nature 2005;433:769-773.

37. Lytle JR, Yario TA, Steitz JA. Target mRNAs are repressed as efficiently by microRNA-binding sites in the $5^{\prime}$ UTR as in the 3' UTR. Proc Natl Acad Sci U S A 2007;104:9667-9672.

38. Ruby JG, Stark A, Johnston WK, Kellis M, Bartel DP, Lai EC. Evolution, biogenesis, expression, and target predictions of a substantially expanded set of Drosophila microRNAs. Genome Res 2007; 17:1850-1864.

39. Fang $Z$, Rajewsky N. The impact of miRNA target sites in coding sequences and in 3'UTRs. PLoS One 2011;6:e18067.

40. Paschou M, Doxakis E. Neurofibromin 1 is a miRNA target in neurons. PLoS One 2012;7:e46773.

41. Subtelny AO, Eichhorn SW, Chen GR, Sive H, Bartel DP. Poly(A)-tail profiling reveals an embryonic switch in translational control. Nature 2014;508:66-71.

42. Parker R, Sheth U. P bodies and the control of mRNA translation and degradation. Mol Cell 2007;25:635-646.

43. Jakymiw A, Lian S, Eystathioy T, et al. Disruption of GW bodies impairs mammalian RNA interference. Nat Cell Biol 2005;7: 1267-1274.

44. Shukla GC, Singh J, Barik S. MicroRNAs: Processing, Maturation, Target Recognition and Regulatory Functions. Mol Cell Pharmacol 2011;3:83-92.

45. Saetrom P, Heale BS, Snøve O Jr, Aagaard L, Alluin J, Rossi JJ. Distance constraints between microRNA target sites dictate efficacy and cooperativity. Nucleic Acids Res 2007;35:2333-2342.

46. Arvey A, Larsson E, Sander C, Leslie CS, Marks DS. Target 
mRNA abundance dilutes microRNA and siRNA activity. Mol Syst Biol 2010;6:363.

47. Reyes-Herrera PH, Ficarra E. One decade of development and evolution of microRNA target prediction algorithms. Genomics Proteomics Bioinformatics 2012;10:254-263.

48. Helwak A, Kudla G, Dudnakova T, Tollervey D. Mapping the human miRNA interactome by CLASH reveals frequent noncanonical binding. Cell 2013;153:654-665.

49. Brodersen P, Voinnet O. Revisiting the principles of microRNA target recognition and mode of action. Nat Rev Mol Cell Biol 2009;10:141-148.

50. Choi WY, Giraldez AJ, Schier AF. Target protectors reveal dampening and balancing of Nodal agonist and antagonist by miR- 430 . Science 2007;318:271-274.

51. Staton AA, Knaut H, Giraldez AJ. miRNA regulation of Sdf1 chemokine signaling provides genetic robustness to germ cell migration. Nat Genet 2011;43:204-211.

52. Knauss JL, Bian S, Sun T. Plasmid-based target protectors allow specific blockade of miRNA silencing activity in mammalian developmental systems. Front Cell Neurosci 2013;7:163.

53. Lau P, Verrier JD, Nielsen JA, Johnson KR, Notterpek L, Hudson LD. Identification of dynamically regulated microRNA and mRNA networks in developing oligodendrocytes. J Neurosci 2008; 28:11720-11730.

54. Dorval V, Smith PY, Delay C, et al. Gene network and pathway analysis of mice with conditional ablation of Dicer in post-mitotic neurons. PLoS One 2012;7:e44060.

55. Edbauer D, Neilson JR, Foster KA, et al. Regulation of synaptic structure and function by FMRP-associated microRNAs miR-125b and miR-132. Neuron 2010;65:373-384.

56. Lee K, Kim JH, Kwon OB, et al. An activity-regulated microRNA, miR-188, controls dendritic plasticity and synaptic transmission by downregulating neuropilin-2. J Neurosci 2012;32:5678-5687.

57. Tognini P, Putignano E, Coatti A, Pizzorusso T. Experience-dependent expression of miR-132 regulates ocular dominance plasticity. Nat Neurosci 2011;14:1237-1239.

58. Wibrand K, Panja D, Tiron A, et al. Differential regulation of mature and precursor microRNA expression by NMDA and metabotropic glutamate receptor activation during LTP in the adult dentate gyrus in vivo. Eur J Neurosci 2010;31:636-645.

59. Ashraf SI, Kunes S. A trace of silence: memory and microRNA at the synapse. Curr Opin Neurobiol 2006;16:535-539.

60. Bramham CR, Wells DG. Dendritic mRNA: transport, translation and function. Nat Rev Neurosci 2007;8:776-789.

61. Sutton MA, Schuman EM. Dendritic protein synthesis, synaptic plasticity, and memory. Cell 2006;127:49-58.

62. Steward O, Schuman EM. Protein synthesis at synaptic sites on dendrites. Annu Rev Neurosci 2001;24:299-325.

63. Torre ER, Steward O. Demonstration of local protein synthesis within dendrites using a new cell culture system that permits the isolation of living axons and dendrites from their cell bodies. J Neurosci 1992;12:762-772.

64. Kosik KS, Krichevsky AM. The Elegance of the MicroRNAs: A Neuronal Perspective. Neuron 2005;47:779-782.

65. Krichevsky AM, King KS, Donahue CP, Khrapko K, Kosik KS. A microRNA array reveals extensive regulation of microRNAs during brain development. RNA 2003;9:1274-1281.

66. Lagos-Quintana M, Rauhut R, Yalcin A, Meyer J, Lendeckel W, Tuschl T. Identification of tissue-specific microRNAs from mouse. Curr Biol 2002;12:735-739.

67. Sempere LF, Freemantle S, Pitha-Rowe I, Moss E, Dmitrovsky E, Ambros V. Expression profiling of mammalian microRNAs uncovers a subset of brain-expressed microRNAs with possible roles in murine and human neuronal differentiation. Genome Biol 2004; $5: R 13$.

68. Lugli G, Larson J, Martone ME, Jones Y, Smalheiser NR. Dicer and $\mathrm{eIF} 2 \mathrm{c}$ are enriched at postsynaptic densities in adult mouse brain and are modified by neuronal activity in a calpain-dependent manner. J Neurochem 2005;94:896-905.

69. Johnson R, Noble W, Tartaglia GG, Buckley NJ. Neurodegeneration as an RNA disorder. Prog Neurobiol 2012;99:293-315.

70. Salta E, De Strooper B. Non-coding RNAs with essential roles in neurodegenerative disorders. Lancet Neurol 2012;11:189-200.

71. Schratt GM, Tuebing F, Nigh EA, et al. A brain-specific microRNA regulates dendritic spine development. Nature 2006; 439:283-289.

72. Hering H, Sheng M. Dendritic spines: structure, dynamics and regulation. Nat Rev Neurosci 2001;2:880-888.

73. Spruston N. Pyramidal neurons: dendritic structure and synaptic integration. Nat Rev Neurosci 2008;9:206-221.

74. Wayman GA, Davare M, Ando $\mathrm{H}$, et al. An activity-regulated microRNA controls dendritic plasticity by down-regulating p250GAP. Proc Natl Acad Sci U S A 2008;105:9093-9098.

75. Taniguchi S, Liu H, Nakazawa T, Yokoyama K, Tezuka T, Yamamoto T. p250GAP, a neural RhoGAP protein, is associated with and phosphorylated by Fyn. Biochem Biophys Res Commun 2003;306:151-155.

76. Vo N, Klein ME, Varlamova O, et al. A cAMP-response element binding protein-induced microRNA regulates neuronal morphogenesis. Proc Natl Acad Sci USA 2005;102:16426-16431.

77. Impey S, Davare M, Lesiak A, et al. An activity-induced microRNA controls dendritic spine formation by regulating Rac1-PAK signaling. Mol Cell Neurosci 2010;43:146-156.

78. Baudet ML, Bellon A, Holt CE. Role of microRNAs in Semaphorin function and neural circuit formation. Semin Cell Dev Biol 2013;24:146-155.

79. Chandrasekar V, Dreyer JL. microRNAs miR-124, let-7d and miR-181a regulate cocaine-induced plasticity. Mol Cell Neurosci 2009;42:350-362.

80. Hollander JA, Im HI, Amelio AL, et al. Striatal microRNA controls cocaine intake through CREB signalling. Nature 2010;466: 197-202.

81. Kocerha J, Faghihi MA, Lopez-Toledano MA, et al. MicroRNA219 modulates NMDA receptor-mediated neurobehavioral dysfunction. Proc Natl Acad Sci USA 2009;106:3507-3512.

82. Lippi G, Steinert JR, Marczylo EL, et al. Targeting of the Arpc3 actin nucleation factor by $\mathrm{miR}-29 \mathrm{a} / \mathrm{b}$ regulates dendritic spine morphology. J Cell Biol 2011;194:889-904.

83. Numakawa $T$, Richards $M$, Adachi $N$, Kishi S, Kunugi $H$, Hashido K. MicroRNA function and neurotrophin BDNF. Neurochem Int 2011;59:551-558.

84. Kress M, Hüttenhofer A, Landry M, et al. microRNAs in noci- 
ceptive circuits as predictors of future clinical applications. Front Mol Neurosci 2013;6:33

85. Orlova IA, Alexander GM, Qureshi RA, et al. MicroRNA modulation in complex regional pain syndrome. J Transl Med 2011;9: 195

86. He Y, Yang C, Kirkmire CM, Wang ZJ. Regulation of opioid tolerance by let-7 family microRNA targeting the mu opioid receptor. J Neurosci 2010;30:10251-10258.

87. Bai G, Ambalavanar R, Wei D, Dessem D. Downregulation of selective microRNAs in trigeminal ganglion neurons following inflammatory muscle pain. Mol Pain 2007;3:15

88. Poh KW, Yeo JF, Ong WY. MicroRNA changes in the mouse prefrontal cortex after inflammatory pain. Eur J Pain 2011;15:801, e1-e12.

89. Recchiuti A, Krishnamoorthy S, Fredman G, Chiang N, Serhan $\mathrm{CN}$. MicroRNAs in resolution of acute inflammation: identification of novel resolvin D1-miRNA circuits. FASEB J 2011;25:544-560.

90. Xu ZZ, Zhang L, Liu T, et al. Resolvins RvE1 and RvD1 attenuate inflammatory pain via central and peripheral actions. Nat Med 2010;16:592-597.

91. Li H, Shen L, Ma C, Huang Y. Differential expression of miRNAs in the nervous system of a rat model of bilateral sciatic nerve chronic constriction injury. Int J Mol Med 2013;32:219-226.

92. von Schack D, Agostino MJ, Murray BS, et al. Dynamic changes in the microRNA expression profile reveal multiple regulatory mechanisms in the spinal nerve ligation model of neuropathic pain. PLoS One 2011;6:e17670.

93. Soreq H, Wolf Y. NeurimmiRs: microRNAs in the neuroimmune interface. Trends Mol Med 2011;17:548-555.

94. Uceyler N, Eberle T, Rolke R, Birklein F, Sommer C. Differential expression patterns of cytokines in complex regional pain syndrome. Pain 2007;132:195-205.

95. Pabreja K, Dua K, Sharma S, Padi SS, Kulkarni SK. Minocycline attenuates the development of diabetic neuropathic pain: possible anti-inflammatory and anti-oxidant mechanisms. Eur J Pharmacol 2011;661:15-21.

96. Bierhaus A, Nawroth PP. Critical evaluation of mouse models used to study pain and loss of pain perception in diabetic neuropathy. Exp Clin Endocrinol Diabetes 2012;120:188-190.

97. Lehmann SM, Rosenberger K, Kruger C, et al. Extracellularly delivered single-stranded viral RNA causes neurodegeneration dependent on TLR7. J Immunol 2012;189:1448-1458.

98. Park CK, Xu ZZ, Berta T, et al. Extracellular microRNAs activate nociceptor neurons to elicit pain via TLR7 and TRPA1. Neuron 2014;82:47-54.

99. Zhou Q, Souba WW, Croce CM, Verne GN. MicroRNA-29a regulates intestinal membrane permeability in patients with irritable bowel syndrome. Gut 2010;59:775-784.

100. Sanches F, Burkhard F, Kessler T, Kuhn A, Draeger A, Monastyrskaya K. MicroRNAs may mediate the down-regulation of neurokinin-1 receptor in chronic bladder pain syndrome. Am J Pathol 2010;176:288-303.

101. Monastyrskaya K, Sanchez-Freire V, Hashemi Gheinani A, et al. miR-199a-5p regulates urothelial permeability and may play a role in bladder pain syndrome. Am J Pathol 2013;182:431-448.

102. Burney RO, Hamilton AE, Aghajanova L, et al. MicroRNA ex- pression profiling of eutopic secretory endometrium in women with versus without endometriosis. Mol Hum Reprod 2009;15:625-631.

103. Sengupta JN, Pochiraju S, Kannampalli P, et al. MicroRNA-mediated GABA Aalpha-1 receptor subunit down-regulation in adult spinal cord following neonatal cystitis-induced chronic visceral pain in rats. Pain 2013;154:59-70.

104. Zhao C, Huang C, Weng T, Xiao X, Ma H, Liu L. Computational prediction of MicroRNAs targeting GABA receptors and experimental verification of miR-181, miR-216 and miR-203 targets in GABA-A receptor. BMC Res Notes 2012;5:91.

105. Aldrich BT, Frakes EP, Kasuya J, Hammond DL, Kitamoto T. Changes in expression of sensory organ-specific microRNAs in rat dorsal root ganglia in association with mechanical hypersensitivity induced by spinal nerve ligation. Neuroscience 2009;164:711-723.

106. Bali KK, Kuner R. Noncoding RNAs: key molecules in understanding and treating pain. Trends Mol Med 2014;20:437-448.

107. Favereaux A, Thoumine O, Bouali-Benazzouz R, et al. Bidirectional integrative regulation of Cav1.2 calcium channel by microRNA miR-103: role in pain. EMBO J 2011;30:3830-3841.

108. Lin CR, Chen KH, Yang CH, Huang HW, Sheen-Chen SM. Intrathecal miR-183 delivery suppresses mechanical allodynia in mononeuropathic rats. Eur J Neurosci 2014;39:1682-1689.

109. Sakai A, Saitow F, Miyake N, Miyake K, Shimada T, Suzuki H. miR-7a alleviates the maintenance of neuropathic pain through regulation of neuronal excitability. Brain 2013;136:2738-2750.

110. Strickland ER, Hook MA, Balaraman S, Huie JR, Grau JW, Miranda RC. MicroRNA dysregulation following spinal cord contusion: implications for neural plasticity and repair. Neuroscience 2011;186:146-160.

111. Arai M, Genda Y, Ishikawa M, Shunsuke T, Okabe T, Sakamoto A. The miRNA and mRNA changes in rat hippocampi after chronic constriction injury. Pain Med 2013;14:720-729.

112. Bhalala OG, Pan L, Sahni V, et al. microRNA-21 regulates astrocytic response following spinal cord injury. J Neurosci 2012;32: 17935-17947.

113. Chen HP, Zhou W, Kang LM, et al. Intrathecal miR-96 inhibits Nav1.3 expression and alleviates neuropathic pain in rat following chronic construction injury. Neurochem Res 2014;39:76-83.

114. Imai S, Saeki M, Yanase M, et al. Change in microRNAs associated with neuronal adaptive responses in the nucleus accumbens under neuropathic pain. J Neurosci 2011;31:15294-15299.

115. Kusuda R, Cadetti F, Ravanelli MI, et al. Differential expression of microRNAs in mouse pain models. Mol Pain 2011;7:17.

116. Kynast KL, Russe OQ, Moser CV, Geisslinger G, Niederberger E. Modulation of central nervous system-specific microRNA-124a alters the inflammatory response in the formalin test in mice. Pain 2013;154:368-376.

117. Nakanishi K, Nakasa T, Tanaka N, et al. Responses of microRNAs 124a and 223 following spinal cord injury in mice. Spinal Cord 2010;48:192-196.

118. Ni J, Gao Y, Gong S, Guo S, Hisamitsu T, Jiang X. Regulation of mu-opioid type 1 receptors by microRNA134 in dorsal root ganglion neurons following peripheral inflammation. Eur J Pain 2013; 17:313-323.

119. Strickland IT, Richards L, Holmes FE, Wynick D, Uney JB, Wong LF. Axotomy-induced miR-21 promotes axon growth in 
adult dorsal root ganglion neurons. PLoS One 2011;6:e23423.

120. Tam Tam S, Bastian I, Zhou XF, et al. MicroRNA-143 expression in dorsal root ganglion neurons. Cell Tissue Res 2011;346:163-173.

121. Willemen HL, Huo XJ, Mao-Ying QL, Zijlstra J, Heijnen CJ, Kavelaars A. MicroRNA-124 as a novel treatment for persistent hyperalgesia. J Neuroinflammation 2012;9:143.

122. Wu D, Raafat M, Pak E, Hammond S, Murashov AK. MicroRNA machinery responds to peripheral nerve lesion in an injury-regulated pattern. Neuroscience 2011;190:386-397.

123. Bredy TW, Lin Q, Wei W, Baker-Andresen D, Mattick JS. MicroRNA regulation of neural plasticity and memory. Neurobiol Learn Mem 2011;96:89-94.

124. Seminowicz DA, Laferriere AL, Millecamps M, Yu JS, Coderre TJ, Bushnell MC. MRI structural brain changes associated with sensory and emotional function in a rat model of long-term neuropathic pain. Neuroimage 2009;47:1007-1014.

125. Mutso AA, Radzicki D, Baliki MN, et al. Abnormalities in hippocampal functioning with persistent pain. J Neurosci 2012;32:57475756.

126. Baliki MN, Geha PY, Fields HL, Apkarian AV. Predicting value of pain and analgesia: nucleus accumbens response to noxious stimuli changes in the presence of chronic pain. Neuron 2010;66:149-160.

127. Mishra PJ, Bertino JR. MicroRNA polymorphisms: the future of pharmacogenomics, molecular epidemiology and individualized medicine. Pharmacogenomics 2009;10:399-416.

128. LaCroix-Fralish ML, Austin JS, Zheng FY, Levitin DJ, Mogil JS. Patterns of pain: meta-analysis of microarray studies of pain. Pain 2011;152:1888-1898.

129. Wu M, Jolicoeur N, Li Z, et al. Genetic variations of microRNAs in human cancer and their effects on the expression of miRNAs.
Carcinogenesis 2008;29:1710-1716.

130. Glinsky GV. Disease phenocode analysis identifies SNP-guided microRNA maps (MirMaps) associated with human "master" disease genes. Cell Cycle 2008;7:3680-3694.

131. Valadi H, Ekstrom K, Bossios A, Sjostrand M, Lee JJ, Lotvall JO. Exosome-mediated transfer of mRNAs and microRNAs is a novel mechanism of genetic exchange between cells. Nat Cell Biol 2007;9:654-659.

132. Lakhal S, Wood MJ. Exosome nanotechnology: an emerging paradigm shift in drug delivery: exploitation of exosome nanovesicles for systemic in vivo delivery of RNAi heralds new horizons for drug delivery across biological barriers. Bioessays 2011;33:737-741.

133. McMahon SB, Malcangio M. Current challenges in glia-pain biology. Neuron 2009;64:46-54.

134. Echeverry S, Shi XQ, Rivest S, Zhang J. Peripheral nerve injury alters blood-spinal cord barrier functional and molecular integrity through a selective inflammatory pathway. J Neurosci 2011;31: 10819-10828.

135. Ebert MS, Sharp PA. Emerging roles for natural microRNA sponges. Curr Biol 2010;20:R858-861

136. Haraguchi T, Ozaki Y, Iba H. Vectors expressing efficient RNA decoys achieve the long-term suppression of specific microRNA activity in mammalian cells. Nucleic Acids Res 2009;37:e43.

137. Carmell MA, Zhang L, Conklin DS, Hannon GJ, Rosenquist TA. Germline transmission of RNAi in mice. Nat Struct Biol 2003; 10:91-92.

138. Pfeifer A, Eigenbrod S, Al-Khadra S, et al. Lentivector-mediated RNAi efficiently suppresses prion protein and prolongs survival of scrapie-infected mice. J Clin Invest 2006;116:3204-3210. 